\title{
The Austrian Corona Panel Project: monitoring individual and societal dynamics amidst the COVID-19 crisis
}

\author{
Bernhard Kittel $^{1}$ - Sylvia Kritzinger ${ }^{2}$ - Hajo Boomgaarden ${ }^{3}$ - Barbara Prainsack ${ }^{4}$. \\ Jakob-Moritz Eberl ${ }^{3}$ - Fabian Kalleitner ${ }^{1}$ - Noëlle S. Lebernegg ${ }^{3}$. \\ Julia Partheymüller ${ }^{5}$. Carolina Plescia ${ }^{2} \cdot$ David W. Schiestl $^{1} \cdot$ Lukas Schlogl $^{4}$
}

Published online: 22 October 2020

(c) The Author(s) 2020

\begin{abstract}
Systematic and openly accessible data are vital to the scientific understanding of the social, political, and economic consequences of the COVID-19 pandemic. This article introduces the Austrian Corona Panel Project (ACPP), which has generated a unique, publicly available data set from late March 2020 onwards. ACPP has been designed to capture the social, political, and economic impact of the COVID19 crisis on the Austrian population on a weekly basis. The thematic scope of the study covers several core dimensions related to the individual and societal impact of the COVID-19 crisis. The panel survey has a sample size of approximately 1500 respondents per wave. It contains questions that are asked every week, complemented by domain-specific modules to explore specific topics in more detail. The article presents details on the data collection process, data quality, the potential for analysis, and the modalities of data access pertaining to the first ten waves of the study.
\end{abstract}

Keywords Behaviour and attitudes · Coronavirus $\cdot$ COVID-19 $\cdot$ Online panel survey $\cdot$ Pandemic response $\cdot$ Survey data $\cdot$ Social sciences

\section{Introduction}

The COVID-19 crisis has fundamentally changed everyday life in Austria as well as in many other countries. Some people have been seriously ill. Some have experienced income or job losses, and those fortunate enough to work from home often struggle with combining housework and childcare. Students and their families have faced the various challenges related to home schooling. In sum, the Austrian population has experienced a period of rapid change. However, the challenges and

Bernhard Kittel

bernhard.kittel@univie.ac.at

Extended author information available on the last page of the article 
implications for every person and family have been different. Given the severity of the COVID-19 crisis and its unprecedented disruption of many areas of social and economic life, it is vital to be able to systematically track and understand the consequences of such disruptions among the general population. Researchers from various areas need access to data in an open and free manner. This allows generating systematic scientific evidence and thereby contributes to the understanding of the crisis.

In this article, we present the publicly available data set of the first ten survey waves of the Austrian Corona Panel Project (ACPP), which has been a multidisciplinary effort of social scientists from the University of Vienna investigating how information, attitudes, and behaviours are distributed across the population, and how these develop in the course of the crisis. This unique Austrian data $\operatorname{set}^{1}$ spans the period between the end of March 2020, 2 weeks after the announcement of the general lockdown in Austria, and early June 2020, when the measures curtailing economic activity have been lifted in most sectors (excluding, in particular, culture and sports) and everyday life slowly went back to "normal". Data were collected through a weekly online panel survey with a core set of standard questions (asked every week) and a variety of modules asked once or at longer intervals. The data thus allow to trace individual- and group-level reactions to the crisis and to the political and societal responses, as these evolved over time.

The aim of this article is to introduce the academic community to the data set by describing the research design, the method of data collection, and the basic structure of the data. In the following sections, we first describe the aims of the project, present the data, and discuss some methodological aspects of data collection. We then describe the themes covered in the various waves of the panel and illustrate selected research potentials with some descriptive findings. This discussion is followed by an explanation of data access and a few concluding remarks.

\section{Aims of the survey}

Austria has responded early and with rather strict measures to the COVID-19 pandemic, which resulted in a flat infection curve but generated a near-to-complete economic lockdown for 10 weeks. The responses have brought about various dilemmas. For instance, in the early phase of the pandemic, the Austrian government prioritized infection control measures over any other considerations. This strong focus on public health aspects in the government's and legislators' responses, we argue, was important to contain the number of infections. At the same time, the focus on the threat of the virus temporarily pushed other concerns, such as routine medical care or psychological well-being, into the background.

\footnotetext{
1 An overview of other national (panel) data sets can be found for instance at https://lukaslehner.githu b.io/covid19policytrackers/\#15-national-surveys-with-probability-samples.
} 
After the first phase, ${ }^{2}$ it became visible that the crisis has already widened economic inequality and exposed new groups to economic hardship. Families have struggled with restrictions on movement and home schooling-if not with loss of income. The fear of infecting others has fostered practices of solidarity and, at the same time, concerns for people's own health have deepened existing societal cleavages and created new ones. Large societal challenges, in particular climate change and forced migration, have been superseded by more immediate concerns raised by soaring unemployment and economic hardships. Overall, assessing the desirability of health measures solely against economic and employment objectives, or solely against democratic and civil rights, may lead to neglecting wider societal challenges and its interrelations. The aim of ACPP is, thus, to overcome the dichotomy between public health and economic considerations and to pay attention to the whole range of societal, economic, and political factors that can be affected by a crisis. We seek to contribute to a more encompassing picture of various areas of life during the COVID-19 crisis and investigate individual, societal, and political reactions and how they are related to each other. ${ }^{3}$

The project thus aims for a holistic representation of pandemic responses and their societal consequences by generating a data set that covers a broad range of aspects in a multitude of points in time, and allows to study the causal relationships and interlinkages between the various aspects at the individual and group level. The data allow systematically tracing consequences of the crisis that go beyond measures to control infection and to prevent the overburdening of healthcare systems. We are particularly attentive to non-intended consequences of measures and policies as they can burden those who are already disadvantaged, which in turn negatively affects their social and economic conditions. In view of the serious danger of a "syndemic pandemic" that affects people with worse health status more strongly than others (Bambra et al. 2020), the crisis might deepen societal cleavages and lead to political polarization across Europe and beyond. ACPP aims to contribute a multidisciplinary and integrated view on how different aspects of the handling of the COVID-19 crisis might reinforce or interact with existing inequalities.

Specifically, the project is designed to trace important interrelations between the pandemic and the response measures on the one hand, and different societal fields affected by the pandemic and the externalities of responses on the other hand. It seeks to analyse the interlocking impacts of the COVID-19 crisis on individual behaviour and social dynamics in different societal fields by answering, among others, the following core questions: How do people see the threats at a health and economic level-both for society at large as well as for the person individually? How do people feel about and react to the political measures taken? What do they think

\footnotetext{
${ }^{2}$ Austria gradually reopened from the beginning of May, and had not entered another lockdown at the time of writing this article.

3 As part of the project, we released over 60 (mostly German but also English) scientific blog posts to numerous topics to present first results utilizing the ACPP data. The paragraph summarizes some of the results presented in these blogs that can be accessed at: https://viecer.univie.ac.at/coronapanel/coron a-blog/.
} 


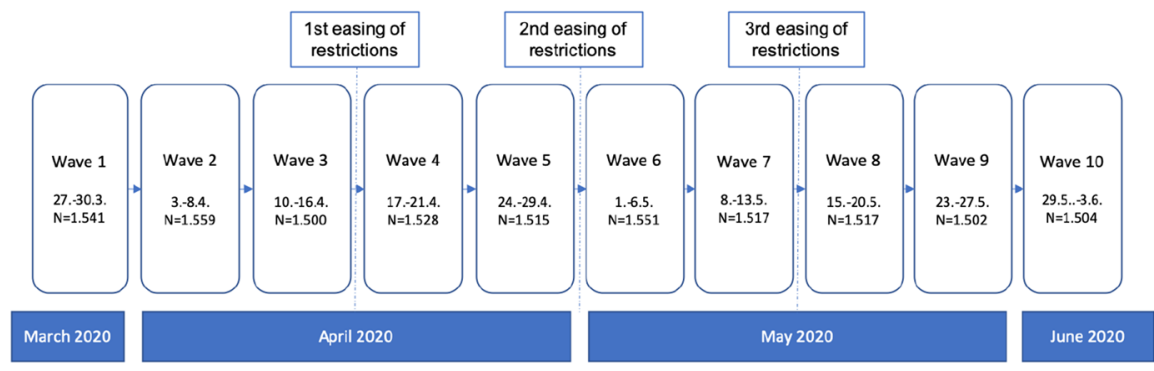

Fig. 1 Schedule of waves

of the democratic and communicative challenges? How have different social groups been affected by the crisis and how do existing inequalities interact with the crisis' impact on individuals and the society?

\section{Study design and data quality}

For these aims, ACPP established an online access panel survey with a sample of 1500 respondents that is representative of the socio-demographic structure of the Austrian population. The panel design means that the same people are being interviewed repeatedly to track changes in a time of rapid change. Questionnaires contain a broad range of questions to capture individual experiences with the COVID-19 and the ensuing economic crisis, asking about respondents' situations, perceptions, emotions, attitudes, preferences, and behaviours. A core set of questions is asked weekly to the same group of people. In addition, (alternating) modules explore certain dimensions in greater detail, yet at greater intervals. This enables us to track important trends in a granular manner in various domains of practice and policy and to focus on important specific questions in particular fields that arise in certain points during the crisis.

\section{Study design and fieldwork period}

Data collection started on 27 March 2020, precisely 14 days after the announcement of the lockdown by the Austrian government on 13 March 2020 (which came into effect on 16 March 2020). The survey started exactly at the time when infection numbers peaked. The severe lockdown measures that were in effect during the first waves of our data collection were subsequently eased in several stages, beginning in the middle of April (see Fig. 1).

Over a period of 10 weeks, the same group of respondents was invited to participate in the weekly survey. Thanks to the short, weekly intervals, the survey is ideally suited to capture the rapidly unfolding societal and individual dynamics amidst the COVID-19 crisis and for a study of the dynamics of public opinion and behaviour during a period of intense crisis communication in a fine-grained way. 
Table 1 Accuracy measures for the raw and weighted data

\begin{tabular}{|c|c|c|c|c|c|c|c|c|c|c|c|}
\hline Variable & W1 & W2 & W3 & W4 & W5 & W6 & W7 & W8 & W9 & W10 & $\begin{array}{l}\text { Post- } \\
\text { stratification } \\
\text { weights? }\end{array}$ \\
\hline Gender $(2 \text { cat. })^{\mathrm{a}}$ & 0.9 & 0.6 & 0.4 & 1.1 & 0.4 & 0.8 & 0.8 & 0.9 & 0.5 & 1.3 & No \\
\hline Age $(6 \text { cat. })^{\mathrm{a}}$ & 3.0 & 2.2 & 2.3 & 2.3 & 2.3 & 2.6 & 2.2 & 2.3 & 2.1 & 2.2 & No \\
\hline Gender*Age (12 cat. $)^{\mathrm{a}}$ & 1.6 & 1.2 & 1.2 & 1.3 & 1.2 & 1.4 & 1.3 & 1.3 & 1.2 & 1.3 & No \\
\hline Education $(5 \text { cat. })^{\mathrm{a}}$ & 7.0 & 7.1 & 7.3 & 7.7 & 7.4 & 7.3 & 7.5 & 7.4 & 7.7 & 7.8 & No \\
\hline Region $(9 \text { cat. })^{\mathrm{a}}$ & 0.4 & 1.0 & 0.4 & 0.6 & 0.5 & 0.3 & 0.3 & 0.5 & 0.5 & 0.3 & No \\
\hline Household size (3 cat.) & 4.4 & 4.1 & 4.3 & 4.4 & 4.0 & 4.3 & 4.4 & 3.8 & 4.7 & 4.4 & No \\
\hline Employment status (4 cat.) & 2.0 & 1.7 & 1.6 & 1.8 & 2.0 & 2.1 & 1.9 & 1.7 & 1.6 & 1.7 & No \\
\hline Migration background (2 cat.) & 3.7 & 3.3 & 2.7 & 2.7 & 2.1 & 2.2 & 2.6 & 2.8 & 1.6 & 1.8 & No \\
\hline Overall (43 cat.) & 3.2 & 3.0 & 3.0 & 3.2 & 3.0 & 3.1 & 3.1 & 3.1 & 3.2 & 3.2 & No \\
\hline Gender $(2 \text { cat. })^{\mathrm{a}}$ & 0.0 & 0.0 & 0.0 & 0.0 & 0.0 & 0.0 & 0.0 & 0.0 & 0.0 & 0.0 & Yes \\
\hline $\operatorname{Age}(6 \text { cat. })^{\mathrm{a}}$ & 0.1 & 0.1 & 0.1 & 0.1 & 0.1 & 0.1 & 0.1 & 0.1 & 0.1 & 0.0 & Yes \\
\hline 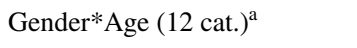 & 0.0 & 0.0 & 0.0 & 0.0 & 0.0 & 0.0 & 0.0 & 0.0 & 0.0 & 0.0 & Yes \\
\hline Education $(5 \text { cat. })^{\mathrm{a}}$ & 0.0 & 0.0 & 0.0 & 0.0 & 0.0 & 0.0 & 0.0 & 0.0 & 0.0 & 0.0 & Yes \\
\hline Region $(9 \text { cat. })^{\mathrm{a}}$ & 0.0 & 0.0 & 0.0 & 0.0 & 0.0 & 0.0 & 0.0 & 0.0 & 0.0 & 0.0 & Yes \\
\hline Household size (3 cat.) & 0.0 & 0.0 & 0.0 & 0.0 & 0.0 & 0.0 & 0.0 & 0.0 & 0.0 & 0.0 & Yes \\
\hline Employment status (4 cat.) & 0.0 & 0.0 & 0.0 & 0.0 & 0.0 & 0.0 & 0.0 & 0.0 & 0.0 & 0.0 & Yes \\
\hline Migration background (2 cat.) & 0.0 & 0.0 & 0.0 & 0.0 & 0.0 & 0.0 & 0.0 & 0.0 & 0.0 & 0.0 & Yes \\
\hline Overall (43 cat.) & 0.0 & 0.0 & 0.0 & 0.0 & 0.0 & 0.0 & 0.0 & 0.0 & 0.0 & 0.0 & Yes \\
\hline
\end{tabular}

Entries are RMSE values (percentage points) calculated based on Table 3 in "Appendix"

${ }^{a}$ Demographics with categories (partially) affected by quotas

\section{Data quality: coverage, accuracy, and weights}

Survey respondents were recruited from a pre-existing online access panel provided by Marketagent.com online research $\mathrm{GmbH}$ (Baden, Austria; certified under ISO 20252). Marketagent has a total of 129,500 registered panellists in Austria and routinely recruits panellists using various channels for off-line recruitment, which includes advertising on television, print media, radio, and billboards, to reduce bias towards heavy online users in its pool. Marketagent had proven to be a reliable data partner in previous academic projects such as the Austrian National Election Study (AUTNES) Online Panel Study 2017-2019 (Aichholzer et al. 2020).

To participate in the survey of the Austrian Corona Panel Project, respondents need to reside in Austria, be at least 14 years old, and have access to the internet (either via smartphone, tablet, or computer). Respondents from the access pool were selected using quota sampling and were invited based on quotas for the following key demographics: age, gender, age*gender, region (Bundesland), municipality size, and educational level.

To assess the accuracy of the raw and weighted data, Table 1 displays the deviations as measured by the root mean square error (RMSE; MacInnis et al. 
2018) for all waves and across a number of demographic variables for which data from official statistics (Statistik Austria 2019) are available. Both the raw and the weighted data are very accurate, with an overall average deviation of about 3 percentage points for the raw data. In the raw data, the largest deviations can be found for educational groups. Further in-depth analysis reveals that these deviations are caused by the underrepresentation of respondents at the lowest level of education-a common non-response problem in most surveys. The second largest deviation is found for household size, with larger households $(3+$ persons $)$ being somewhat overrepresented at the cost of two-person households. Most other deviations are quite small.

The demographic post-stratification weights (W*_WEIGHTD) available in the data set remove the deviations from the population targets completely. Tiny deviations remain for age but those are within the margin of tolerance $(0.1)$ of the iterative-proportional-fitting weighting algorithm (Bergmann 2011) that was used to calculate the weights.

All in all, the survey estimates mirror the target distributions of the Austrian population fairly closely both for quota and other demographic variables. Data users should always keep in mind, though, that data from online access panel surveys with non-probability sampling needs to be interpreted with great care as self-selection, mode, undercoverage, and non-response can still cause biases when studying specific outcomes, especially, when factors are related to the likelihood of respondents entering the panel (Kohler et al. 2019; Cornesse et al. 2020).

\section{Data quality: response rates, retention, and patterns of panel attrition}

The initial response rate in wave 1 was $35.2 \%$ : Out of 4381 invited panellists, 1541 interviews were completed. This response rate can be considered unusually high. For comparison, the initial response rate in wave 1 of the AUTNES Online Panel Study, 2017-2019, was 9.0\%, recruiting from the same access pool of respondents. Thus, the study profited from the fact that many people had to stay at home and were more willing to spend their time by answering survey questions (Dillman et al. 2014; Keusch 2015).

Respondents received 180 credit points $(1.80 €)$ for each wave in which they participated in the panel survey, which took about 19 min to complete on average. If the number of respondents was not sufficiently large, $n \leq 1500$, new respondents were invited a few days after fieldwork started. Figure 2 shows that 1011 of the initial respondents $(65.6 \%)$ from the first wave still took part in wave 10, with varying patterns of unit non-response. The second largest group in wave 10 consists of respondents recruited in the second wave (146), which emphasizes that we were able to motivate respondents to stay active. The black dotted line in Fig. 2 indicates the share of respondents in each wave that completed all previous questionnaires. While this share is clearly decreasing after each wave, still about half (45.5\%) of wave1-respondents (701) completed all ten waves.

The patterns of panel attrition are almost entirely unsystematic. To evaluate which respondents remained active, three regression models were estimated: one 


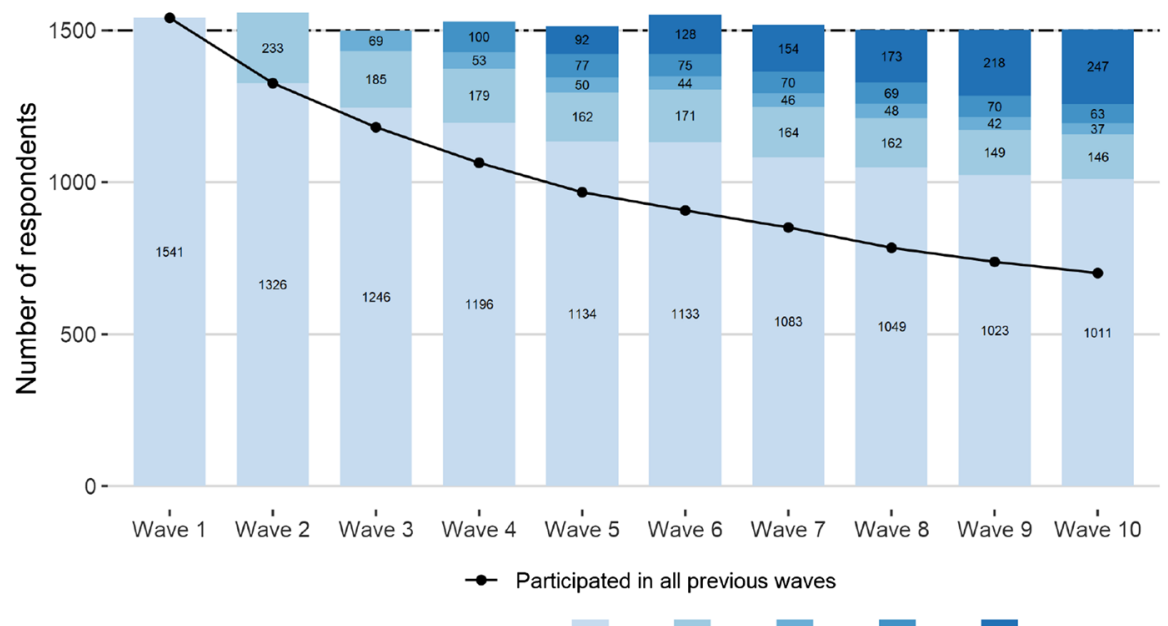

$\begin{array}{llllllll}\text { Wave respondent entered the panel: } & \text { W1 } & \text { W2 } & \text { W3 } & \text { W4 } & \text { W5 or later }\end{array}$

Fig. 2 Composition of waves by panellists' time of entry

explaining which respondents took part in both wave 1 and wave 10 , the second explaining which respondents took part in all ten waves, and the third explaining the number of waves a respondent participated in. Key demographics such as age, gender, age*gender, education, region, household size, employment status, and migration background were used as independent variables. As further predictors respondents' perceived personal and public health-related and economic threats were included in the retention models (see Table 4 in "Appendix" for the full estimation results). Young respondents are less likely to stay active. In particular, young male respondents participated in fewer waves - a familiar pattern that can be found in the context of comparable studies (Aichholzer et al. 2020). Apart from that, only respondents from one regional entity (Burgenland) were somewhat less likely to be retained than others. Otherwise, there are no significant relationships with panel retention. Overall, the analyses show that there are hardly any systematic patterns, implying that panel drop-out has been essentially unrelated to key demographics and perceived COVID-19 threats.

\section{Research potential}

While in the early days of the lockdown the focus of public debate was on individual behaviour and the reduction of infection risk, it soon became clear that the crisis could have lasting and disruptive effects on social life, the economy as well as political views and behaviours. The data enable researchers to study not only general developments like citizens' perceptions of the pandemic, but also how respective policy measures affected behaviour and psychosocial dynamics within individuals and the society at large in a variety of issues. 


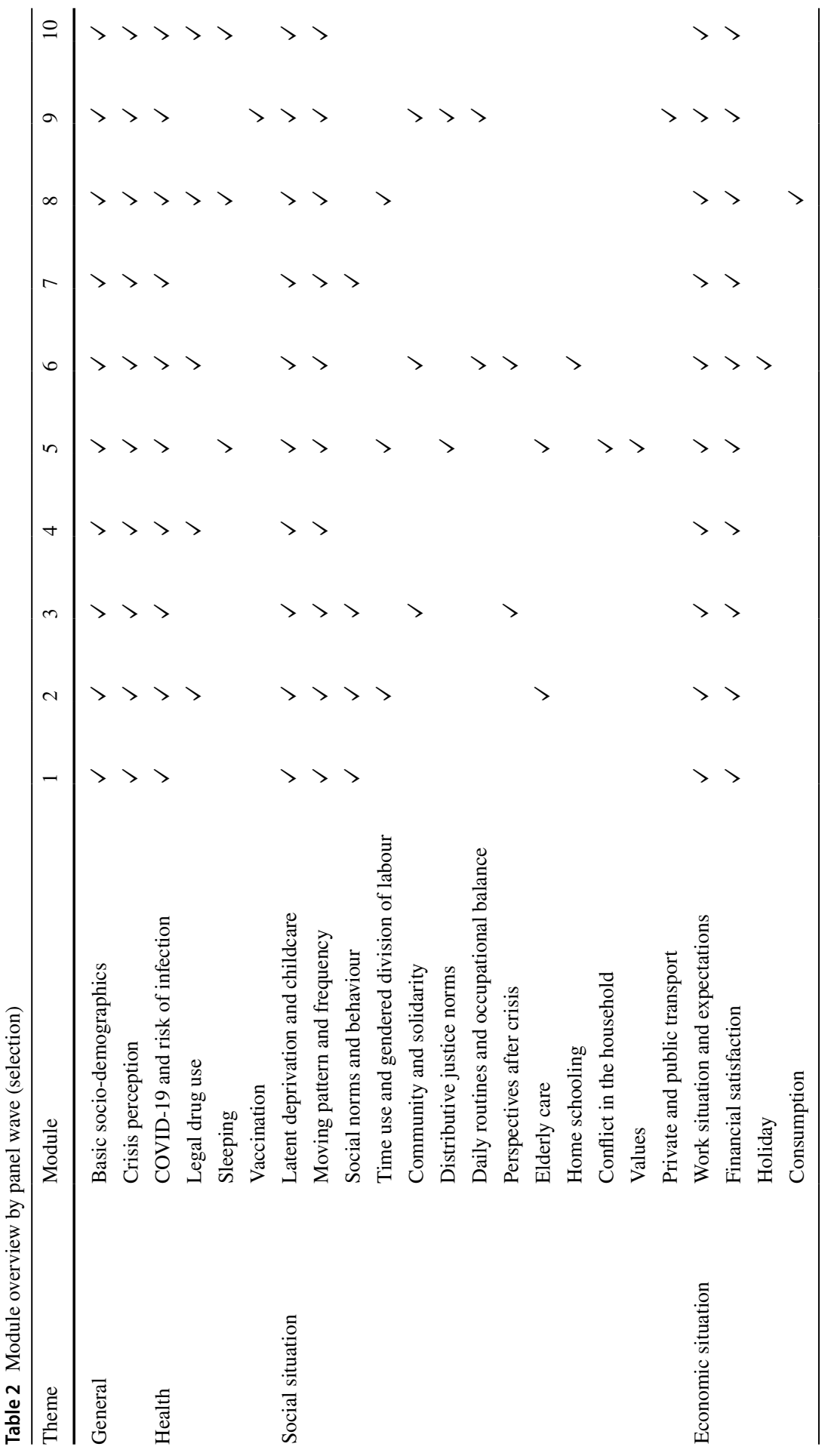




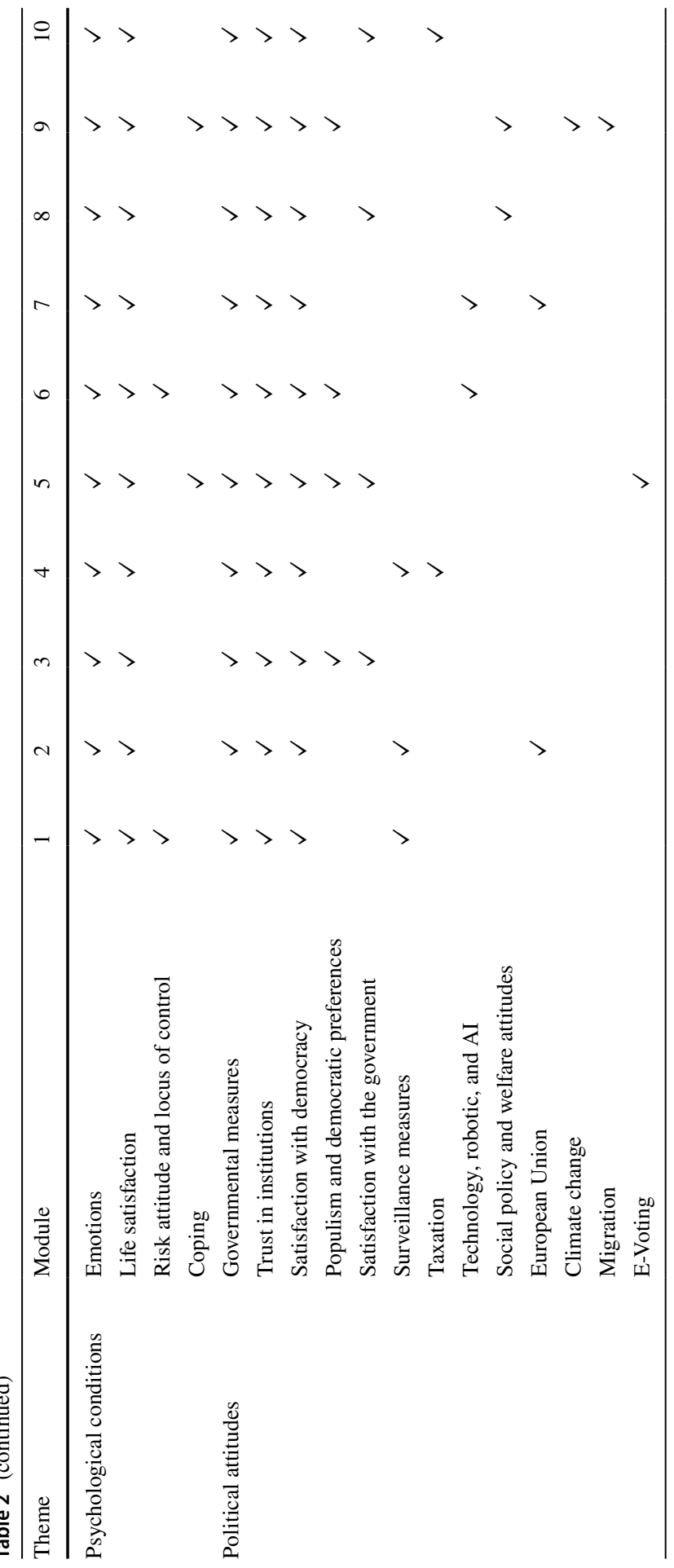

站。 


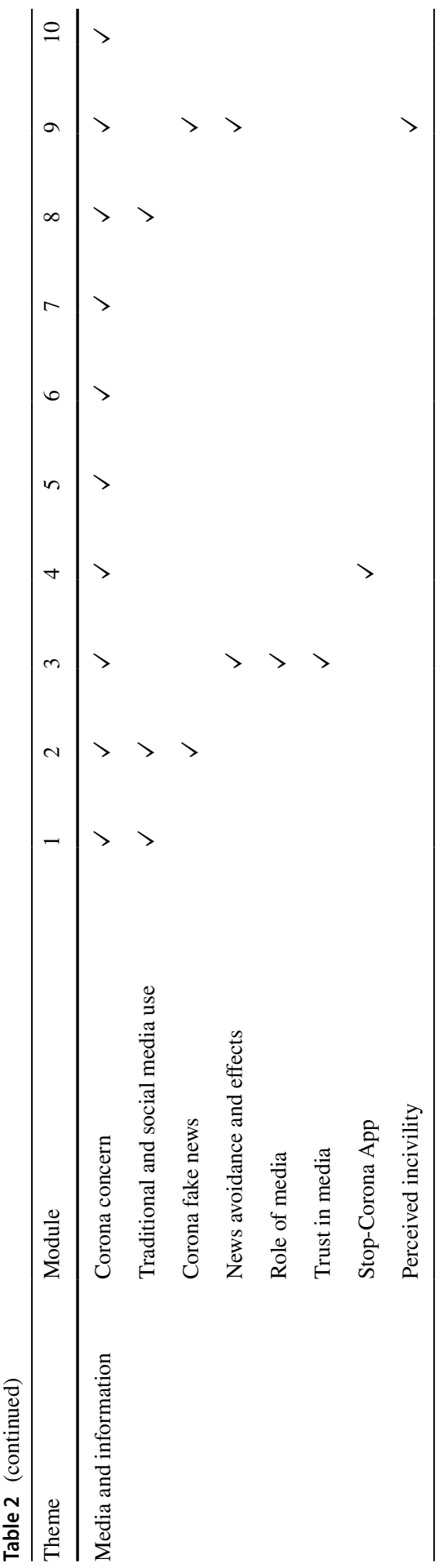


The multidisciplinary approach of ACPP engenders a broad and varied palette of variables, which are included in the questionnaire and can be grouped into six main themes: health, economic situation, social situation, psychological conditions, political attitudes, and media and information. Table 2 illustrates the research potential of the data set, indicating some of the modules of the survey and specifying the waves in which they were included in the questionnaire. ${ }^{4}$ As noted, a core set of variables focusing especially on the immediate impact of COVID-19 on, for instance, employment situations and infection hazards has been asked weekly from wave 1 to wave 10. Many additional items were included in at least two waves and answered by the same respondents so that developments over time cannot only be traced at the aggregate level but also at the individual level. As a result, the data offer a unique possibility to analyse individual and societal short-term responses to crisis dynamics and political pandemic responses and the longer-term evolution of attitudes and behaviours in parallel.

In the following section, we illustrate the research potential of ACPP by outlining some key developments during the crisis. After investigating respondents' subjective threat perceptions, we will focus on some of the main topics already outlined in the introduction: economic situation, psychosocial conditions, political attitudes, and information and communication habits.

\section{Perceptions: threats}

Perceptions are crucial to understanding the links between macro-level conditions and micro-level behavioural as well as attitudinal responses (Hedström and Swedberg 1998). Actual COVID-19 infection risks or unemployment risks may not straightforwardly translate into threat perceptions but depend on various moderating factors. Recent studies already provide first insights that political affiliation and media consumption (Barrios and Hochberg 2020), as well as trust in government, are linked to COVID-19 threat perception (Dryhurst et al. 2020). In a more theoretical sense, Schwarzer argues that perceptions "set[s] the stage for a contemplation process and further elaboration of thoughts about consequences and competencies" (Schwarzer 2008: 6). Hence, focusing on respondents' perceptions should provide us with an idea of how the crisis unfolded from a subjective perspective and enable a better understanding of the attitudinal and behavioural responses that followed.

The share of respondents in the ACPP who perceived health threats reached its high peak already in the first wave of the survey in late March 2020 (Fig. 3). Since then, threat levels have been decreasing and have somewhat levelled out by the mid of May 2020. These results coincide with the number of reported new cases of COVID-19 infections in Austria, although the latter number has dropped faster than the corresponding threat perception. In line with findings from earlier research on health-related risk perception in Great Britain (Rudisill 2013), we found that a

\footnotetext{
4 Because of space restrictions, we had to considerably reduce the amount of detail of the modules in the survey containing nearly 800 variables. For a full overview, see the variable description offered alongside the data.
} 


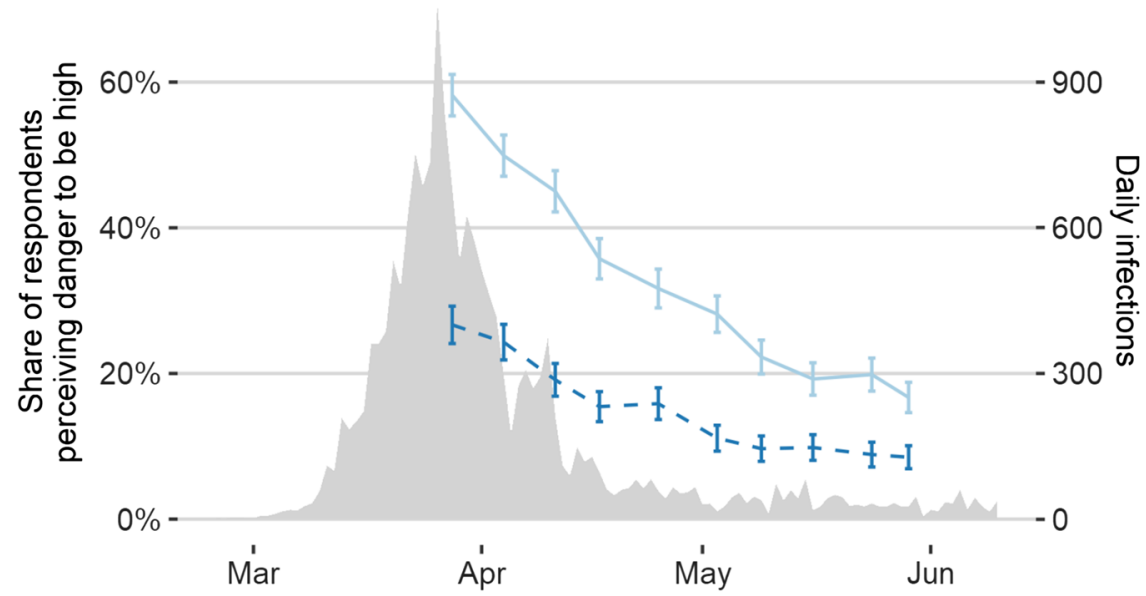

- - For myself — For the Austrian population Infections

Note: Listwise deletion of missings by wave, weighted. Source for COVID-19-cases (BMSGPK 2020). Whiskers indicate $95 \%$ confidence intervals.

Fig. 3 Health threat perception on a personal and a wider public level, combined with official reports of daily infections with the Coronavirus

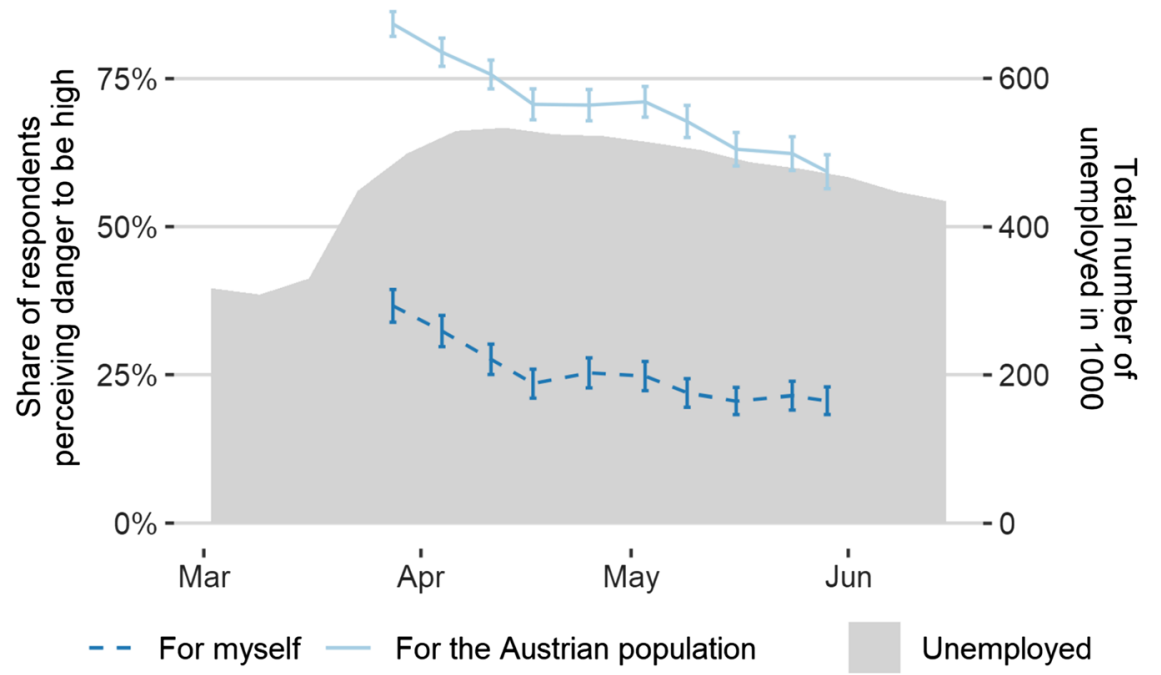

Note: Listwise deletion of missings by wave, weighted. Source for labour market data (BMAFJ 2020). Whiskers indicate $95 \%$ confidence intervals.

Fig. 4 Economic threat perception on a personal and a public level, combined with weekly official reports on the total number of unemployed in Austria 


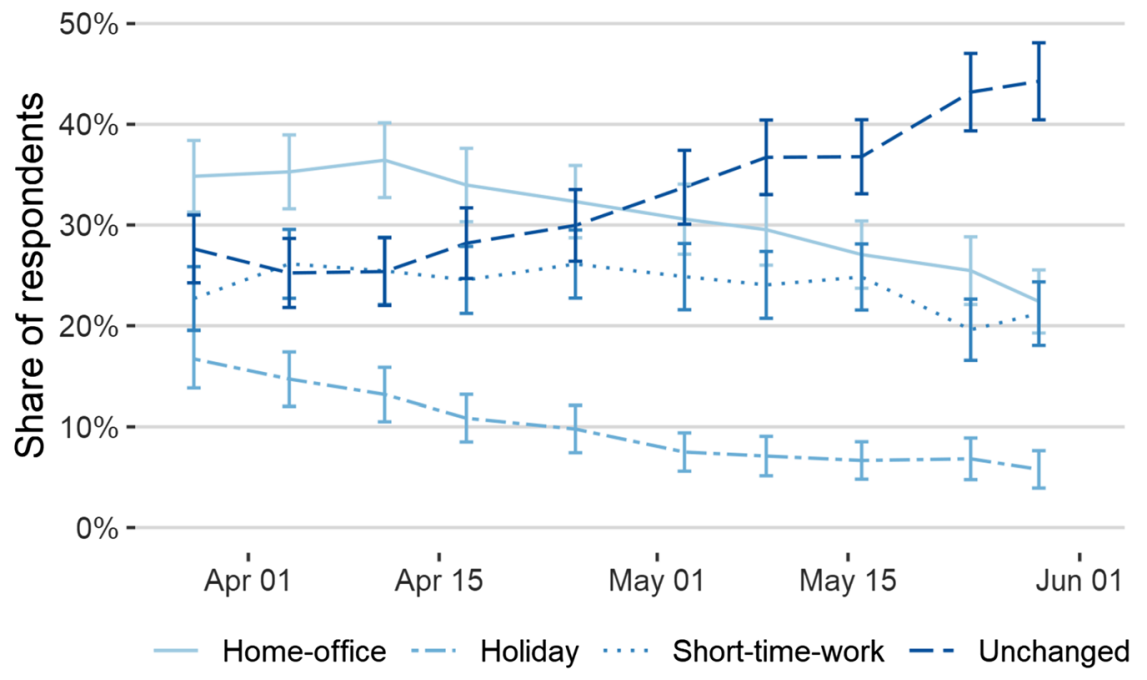

Note: "Unchanged" includes resumption to preceding work conditions, i.e. no home-office, holiday or short-time-work. Share calculated on the basis of all respondents employed at the time of the survey. Listwise deletion of missings by wave, weighted. Whiskers indicate $95 \%$ confidence intervals.

Fig. 5 Employment conditions change over time

substantially larger share of respondents perceived the threat that COVID-19 posed to the wider public to be higher than the personal threat. This might be an effect of the so-called optimism bias (Sharot 2011). This bias can also be found for respondents' perceived economic threats (Fig. 4), which is again in line with the literature suggesting that people assign higher probabilities to occurrences of bad events to people in general compared to themselves (Boomgaarden et al. 2011; Rehm 2016). The differences between perceived personal and public economic threats of COVID19 are even more pronounced than in the domain of health-related threats. However, again they seem to follow a similar decreasing pattern: It is noteworthy that perceived economic threats were already decreasing as unemployment rates were still increasing, suggesting that the economic expectations were extremely unfavourable at the height of the crisis.

\section{Crisis impact: employment conditions}

One explanatory factor of perceived economic threats might be the actual experience of changes in employment status or in employment conditions. As many businesses had to close to comply with governmental measures to curb the pandemic, many people faced severe changes in their employment status or conditions. This can also be seen in aggregate data as the crisis led to a pronounced increase in the unemployment rate in Austria from $8 \%$ in February to the crisis maxima of $13 \%$ in April (BMAFJ 2020). Those who kept their jobs, however, had to deal with changes as well: At the beginning of June 2020, still 1.2 million people in Austria were in 
short-time work, a governmental programme that allows a temporary reduction in working hours while maintaining the employment relationship and granting almost full public wage compensation. Among those who were not affected by changes in employment status or in employment conditions, many had to take annual leave or consume compensatory time, and many were ordered to work from home to meet physical distancing rules. In our data, the change of these statuses over time illustrates the course of the crisis (Fig. 5).

The consumption of annual leave and compensatory time was high in the beginning of the crisis but declined quickly, as employers could only oblige employees to take annual leave days under certain preconditions, such as the consumption of only 2 weeks of vacation from the current year. ${ }^{5}$ The share of short-time work remained at a similar level over the whole investigation period, dropping to a little more than $20 \%$ by the beginning of June 2020. The proportion of people working from home has decreased steadily as well: By June $2020,45 \%$ of the respondents had returned to their usual work practices. The share of employees in our sample who reported at least one change of their employment status or condition during the crisis reached the mark of $70 \%$ in the last wave, indicating the immense impact of the crisis on employment. This also highlights the large variation in work conditions that people faced in this short period of time, which will allow us to fully utilize the potentials of panel data to assess causal effects. With the short period between waves and the stark contrasts in conditions, the ACPP research design enables researchers to closely investigate potential mechanisms.

\section{Emotional responses: loneliness}

Throughout the pandemic, social life was heavily impacted by the measures imposed to control it: The restrictions on movement entailed that many could not see their families and friends. As sociability is one of the fundamental needs of humans that cannot be substituted (Cacioppo and Patrick 2008), we explored the emotional responses to these constraints in our survey, attempting to measure the degree of depression among the respondents. The 9-item battery of emotions can be used to build an index of well-being, and such indices have shown to be highly valid as a screening instrument for depressivity (Krieger et al. 2014).

One of the assessed emotions was the feeling of loneliness. The share of respondents feeling lonely several times a week or more frequently was $16 \%$ by the end of March. In the following weeks, this share declined to $14 \%$ in mid-April but rose again to $17 \%$ by the end of April 2020. Ever since, the share of persons having feelings of loneliness has been decreasing to $11 \%$ by early June 2020 (Fig. 6). While loneliness varies only in a limited way when considering the entire sample, some groups, such as unemployed people and students, had been affected more severely than others. This might be caused by fewer occasions to socialize compared to the pre-Corona situation and has persisted even after many measures had been lifted.

\footnotetext{
5 See 2nd COVID-19 law, BGB1. I Nr. 16/2020 (entered into force March 21, 2020). https://www.ris. bka.gv.at/eli/bgbl/I/2020/16.
} 


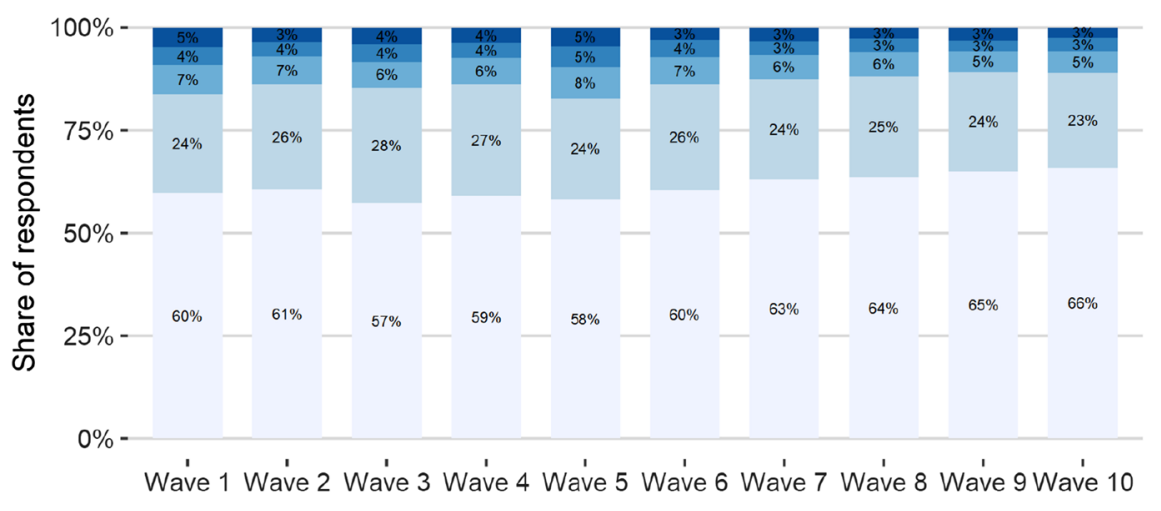

never on some days $\quad$ multiple times a week $\quad$ nearly every day $\square$ daily

Note: Listwise deletion of missings by wave, weighted.

Fig. 6 Distribution of loneliness in Austria during the COVID-19 crisis

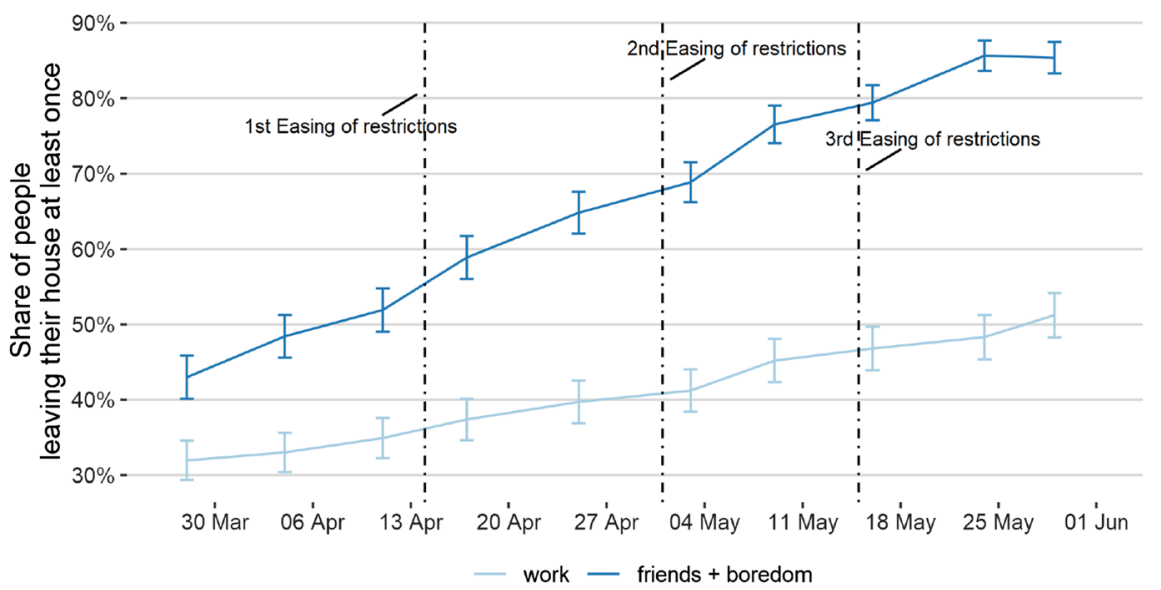

Note: Listwise deletion of missings by wave, weighted. Whiskers indicate $95 \%$ confidence intervals.

Fig. 7 Reasons for leaving the house or flat, including dates of the lifting of restrictions

The lonelier people feel, the less they tend to adhere to self-isolating norms, but show increased orientation on the behaviour of others instead. Through the closely knit assessment of emotions in our data, researchers can gain better understanding of the role of emotions in the crisis as well as disclose interrelations with behaviour.

\section{Behavioural responses: self-isolation}

While perceptions and preferences are important to understand the reference points and possible motivators of individual decisions, behaviour is a tangible 

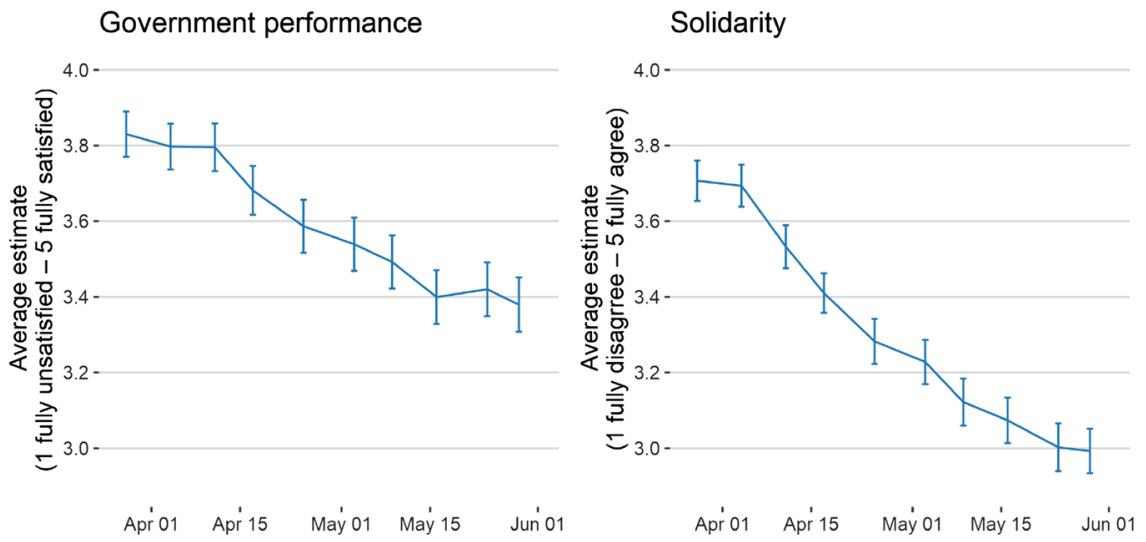

Note: Respondents were asked to answer the following questions: "To this day, how satisfied are you with the work of the government?", "How strong are you agreeing to the following statement: The solidarity in the society has increased in the last week". Listwise deletion of missings by wave, weighted. Whiskers indicate $95 \%$ confidence intervals.

Fig. 8 Satisfaction with government performance and perception of solidarity in Austrian society

measure for the successful implementation of pandemic containment. To address this aspect in a survey context, we asked respondents to specify how often they left their homes for different reasons: As Fig. 7 shows, the respondents reported that self-isolation was high in the early phase of the crisis but had been declining ever since. This result corroborates findings from the analysis of geolocation data from mobile phones (cf. CSH Vienna and TU Wien 2020) and other tools to analyse moving patterns. However, our data provide even more detail: as respondents were asked to give specific reasons for leaving their home, we found significant differences between work and leisure activities as motivations to leave one's home. Our results show that fewer people left their homes to go to work than to pursue leisure activities such as sports, meeting friends, or out of boredom.

Generally, the frequency of leaving the house has been steadily increasing since the beginning of our panel survey. As can be seen in Fig. 7, considerable kinks occur in the curve around each easing of governmental restrictions. This shows a slow boost of out-of-house activities by the regained possibilities to go shopping and visit bars and restaurants. However, further in-depth analyses are necessary to study how the frequency of leaving the house is linked to easings of certain governmental restrictions. Besides these aspects, research may investigate the relationship between self-isolating behaviour and personal or public threat perception. Additionally, the panel survey includes several questions on respondents' own behaviour, their perceptions about the socially expected behaviour, and their perceived behaviour of others. This will enable in-depth research on the role of social norms, the importance of which has been pointed out before (van Bavel et al. 2020), as well as in compliance behaviour in the COVID-19 setting. 

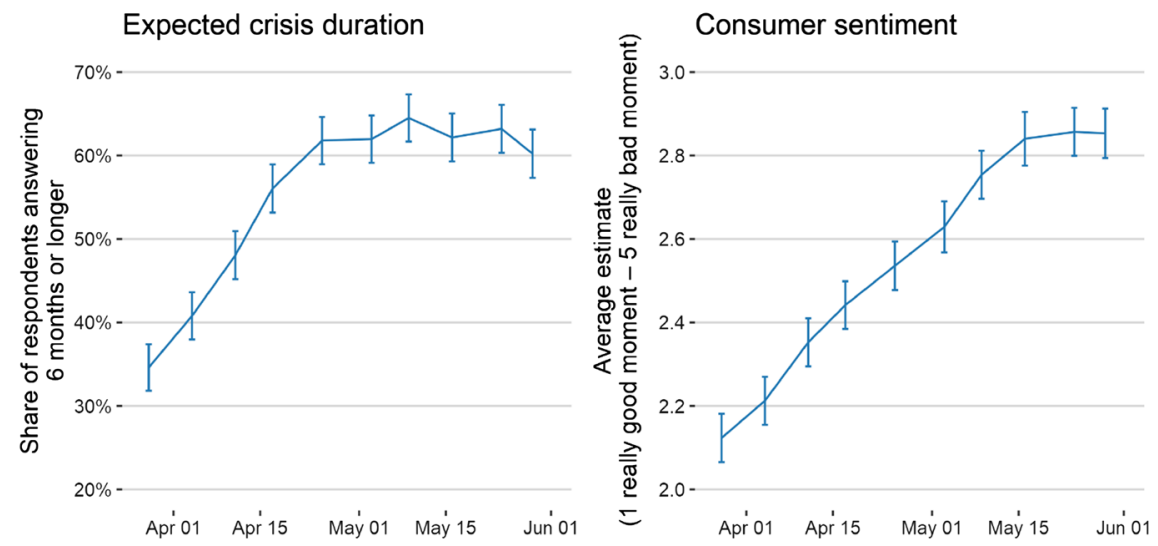

Note: Respondents were asked to answer the following questions: "What do you estimate: How long will it take until life in Austria will be back to normal, that is similar to before the crisis?", "Do you think that now is a good or bad time to buy larger household articles like furniture, a refrigerator, a stove, a tv or similar things?". Listwise deletion of missings by wave, weighted. Whiskers indicate $95 \%$ confidence intervals.

Fig. 9 Share of respondents anticipating the crisis to last another 6 months or longer, and consumer sentiment

\section{Attitudes: government performance, solidarity, crisis expectations, and consumer sentiment}

Political scientists highlighted the large increase in incumbent satisfaction and voting immediately after the crisis (De Vries et al. 2020). This effect (Oneal and Bryan 1995) can also be seen in our data. At the height of the crisis at the end of March 2020, respondents' positive evaluations of governmental performance reached a maximum and decreased steadily thereafter. But, while a considerable amount of literature has been published on rally-around-the-flag effects concerning the COVID19 situation (Bækgaard et al. 2020, Leininger and Schaub 2020, Devine et al. 2020), its causes are still poorly understood. Figure 8 reveals not only high satisfaction with governmental performance but also high levels of perceived public solidarity. Further research might investigate whether both are connected or interdependent, and whether there are implications on both personal behaviour and the perception of other people's behaviour.

Over time, respondents' estimation of the remaining duration of the COVID19-crisis has notably risen: End of March 2020, a share of approximately 35\% anticipated another 6 months of crisis or more. Until the end of April, this proportion had risen above $60 \%$, staying at this level until June 2020. Alongside, consumer sentiment has consistently grown since the first wave of our panel survey, only levelling out since the end of May 2020 (Fig. 9). Hence, notwithstanding significantly increased expectations about the crisis' duration, people do not want to postpone major acquisitions anymore. This coincides with a slow return towards "normal" working conditions and declining economic threat perceptions. Our data allow researchers to explore potential relations to many other aspects, like emotions, selfisolation, or applied coping strategies. 


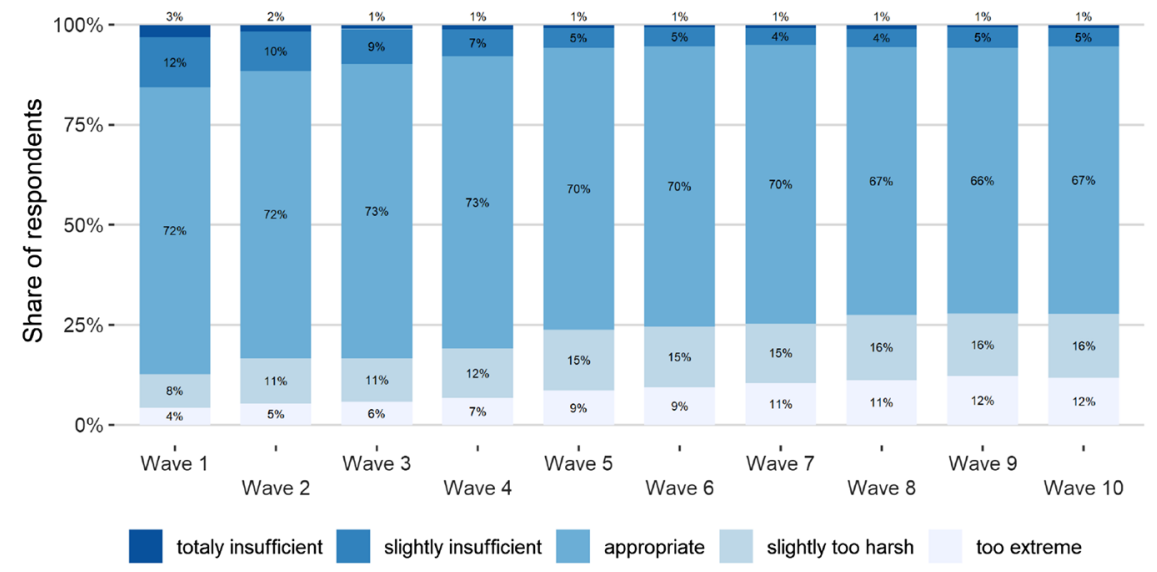

Note: Respondents were asked to answer the following question: "Do you think the reaction of the austrian government in connection to the Coronavirus was sufficient, appropriate or too extreme?". Listwise deletion of missings by wave, weighted. Whiskers indicate $95 \%$ confidence intervals.

Fig. 10 Acceptance of Governmental Measures

\section{Situational preferences: acceptance of governmental measures}

From the beginning of the crisis, the political measures to contain the spread of the coronavirus have been subject to public debate. Nonetheless, the share of respondents who thought that the imposed pandemic containment measures were adequate has been consistently high during the entire crisis, reaching levels between 73 and $66 \%$. Still, we registered changes in the public approval of the measures: While the share of those who would have preferred even stricter regulations slightly exceeded the share of those who wanted to see the measures eased by the end of March 2020, this ratio was reversed soon. By the beginning of June, $28 \%$ of the respondents assessed the measures "rather too strong" or "too extreme" (Fig. 10).

The effectiveness of the measures has been perceived to be very high as well, with disagreement not exceeding 5-8percent in all waves. Taking a look at the respondents' agreement to certain measures, the opinions seem to follow official statements and the governmental schedule: Generally, the approval to all individual measures has been constantly decreasing since they were introduced. But the longer a measure had been in effect, the higher approval remained for the respective measure. With our data, researchers can examine whether or not this is related to rally-around-theflag effects, and how possible interconnections with solidarity and perceptions of other people's behaviour might look like.

\section{Communication: media use and COVID-19 concern}

Media coverage enables broad sections of the population to keep informed about events that take place outside their own world of experience. This is particularly important in times of the COVID-19 pandemic, as the relevance of media 


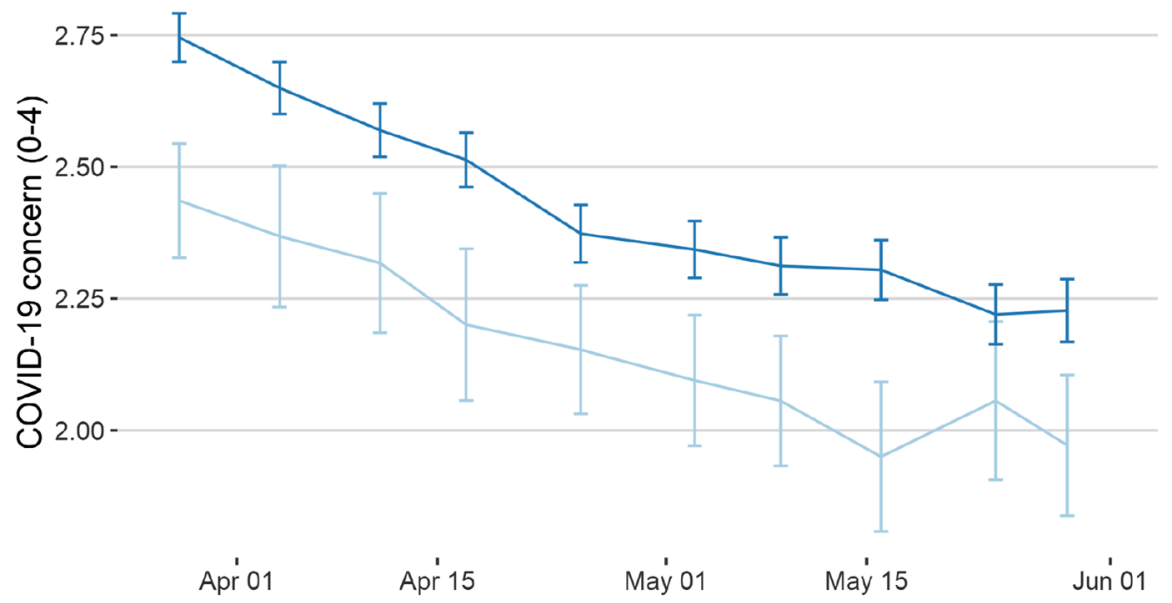

Public news viewer: — once a week or never — several times a week or more

Note: Listwise deletion of missings by wave, weighted. Whiskers indicate $95 \%$ confidence intervals.

Fig. 11 COVID-19 concern and public broadcasting news exposure

information has increased even more due to social distancing, lockdown, and stay at home measures.

But not all citizens get their news from the same sources and particularly during the COVID-19 pandemic international organizations such as the WHO warned of an "infodemic associated with the current pandemic, i.e. the uncontrolled spread of false or misleading information about the virus, which might lead to different levels of COVID-19 concern in the population" (WHO 2020). In such instances international research points to professional journalism and especially a strong public broadcasting service as an essential corrective (Egelhofer et al. 2020; Humprecht et al. 2020).

In fact, during the first weeks of the crisis, up to almost $80 \%$ of the respondents obtained their COVID-19 information more than once a week via the public broadcaster ORF. In Fig. 11, public news exposure was calculated using responses of the first two waves of the data. While the graph does not control for varying news consumption over the period of analysis and represents a simplified model of media effects, it shows clear differences in the level of COVID-19 concern. ${ }^{6}$ In accordance with the aforementioned theory, respondents regularly exposed to news from the public broadcaster were significantly more concerned by the developments of the crisis than those who refused that source of information.

\footnotetext{
${ }^{6}$ COVID-19 concern was operationalized on the basis of the ISSP measure of "environmental concern" (see ISSP Environment III 2010_https://search.gesis.org/research_data/ZA5500) and calculated using the degree of disagreement to the following statements: "There are more important things in life than the coronavirus", "Claims about the crisis are exaggerated", "I am willing to restrict my lifestyle to contain the virus" (inverted), "As long as others do not change their behavior I do not have to change it either".
} 


\section{Data access}

The Scientific Use File (SUF edition) (Kittel et al. 2020a) of the ACPP data covering the first ten survey waves is available for researchers and students from around the globe via download after registration at the Austrian Social Science Data ArchiveAUSSDA (www.aussda.at). In addition, we provide a Public Use File (OA editionopen access edition) (Kittel et al. 2020b) that is suitable for the use by the interested general public that is also available via download from AUSSDA. Data from the ACPP are available in various data formats, including standard data formats such as Stata and SPSS and come together with a methods report and all questionnaires. ACPP is currently continuing data collection on a monthly rhythm. Data from subsequent waves will be released at regular intervals from autumn 2020 via AUSSDA.

\section{Conclusion}

The ACPP data present a unique opportunity to study the effect of an exogenous shock that brought social and economic life to a near-halt in Austrian society. Being a country in which the government has implemented pandemic response fast and hard, followed by loosening measures after a few weeks, Austria offers an exemplary case to study the individual and societal dynamics during a crisis. The weekly individual-level panel structure of this publicly accessible data set provides vast opportunities to explore a variety of causal relationships and allows for most rigorous tests of theory-driven hypotheses. We have described some basic features of the data set and illustrated some potentials for more fine-grained and in-depth analyses in political science, sociology, communication science, economics, social psychology, and public health, among other disciplines. Supporting open science in the digital age, ACPP is looking forward to its data to be used widely and extensively.

Acknowledgements Data collection has been made possible by COVID-19 Rapid Response Grant EICOV20-006 of the Wiener Wissenschafts- und Technologiefonds (WWTF) and financial support by the rectorate of the University of Vienna. Further funding by the Austrian Social Survey (SSÖ), the Vienna Chamber of Labour (Arbeiterkammer Wien), and the Federation of Austrian Industries (Industriellenvereinigung) is gratefully acknowledged. From October 2020, ACPP continues as a research project funded by the Austrian Science Fund (Grant P33907).

Open Access This article is licensed under a Creative Commons Attribution 4.0 International License, which permits use, sharing, adaptation, distribution and reproduction in any medium or format, as long as you give appropriate credit to the original author(s) and the source, provide a link to the Creative Commons licence, and indicate if changes were made. The images or other third party material in this article are included in the article's Creative Commons licence, unless indicated otherwise in a credit line to the material. If material is not included in the article's Creative Commons licence and your intended use is not permitted by statutory regulation or exceeds the permitted use, you will need to obtain permission directly from the copyright holder. To view a copy of this licence, visit http://creativecommons.org/licenses/by/4.0/.

\section{Appendix: The Austrian Corona Panel Project-monitoring societal dynamics amidst the COVID-19 crisis}




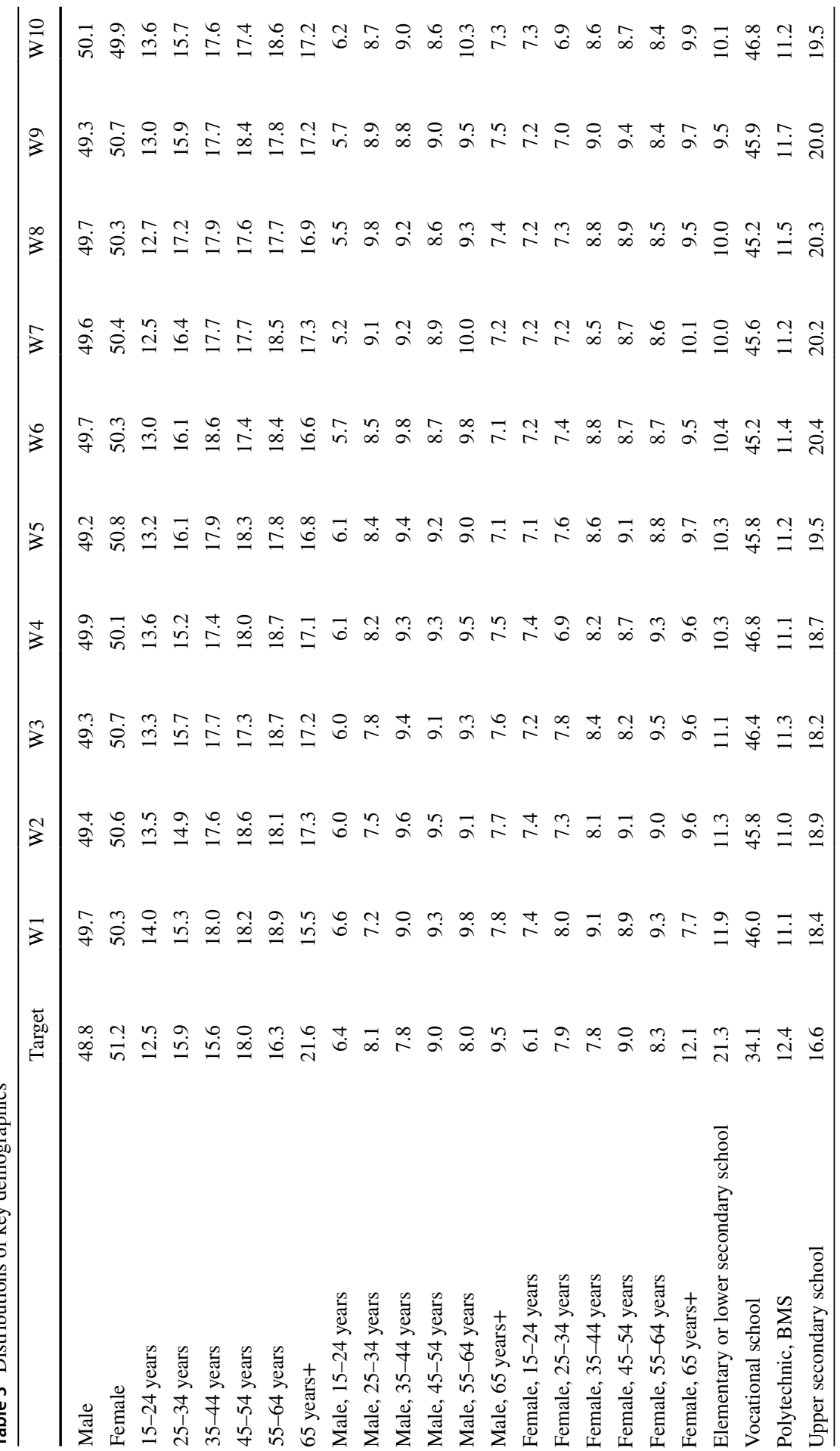

k 


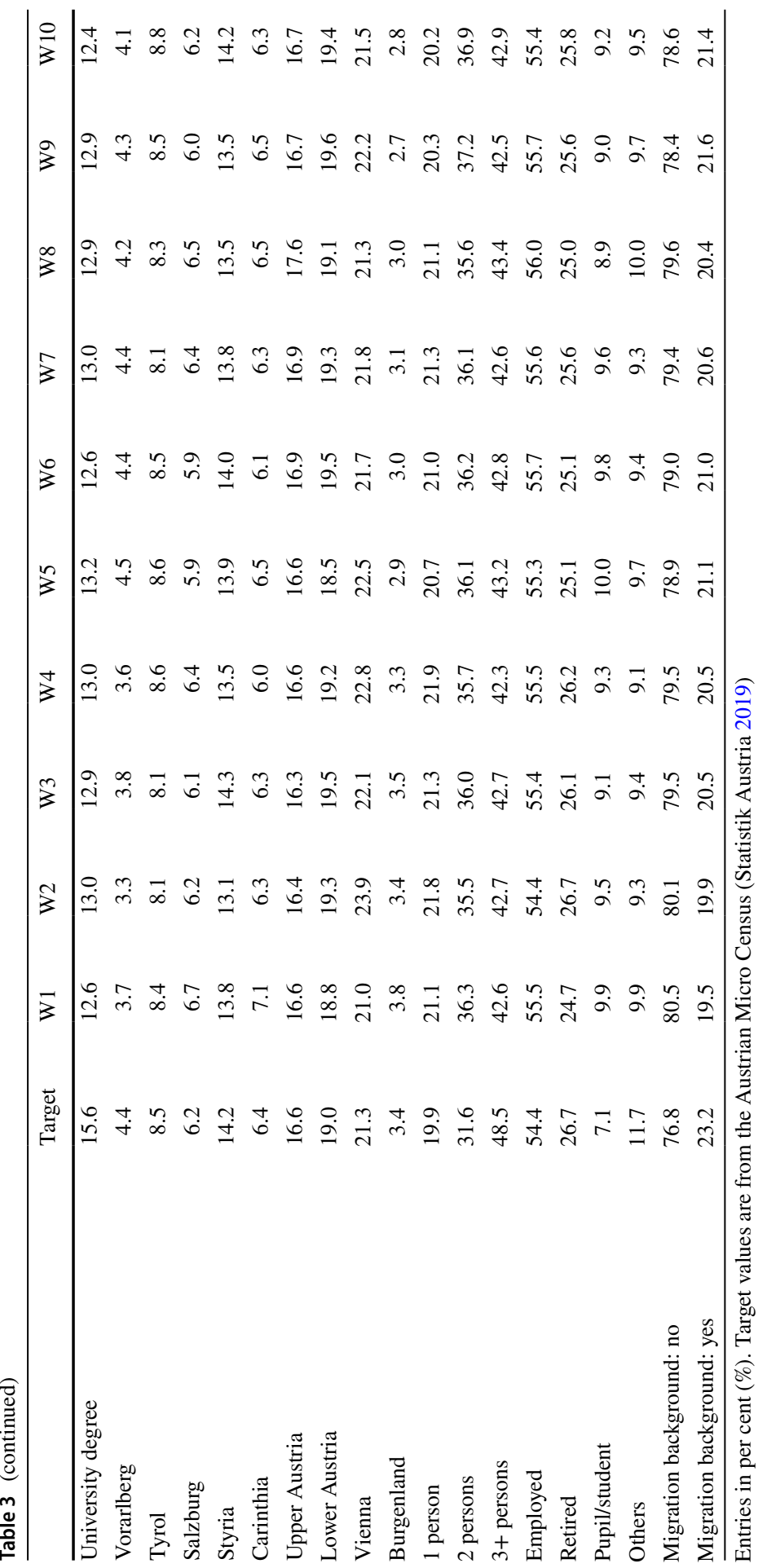


Table 4 Panel retention

(1) Participation in (2) Participation (3) Number of wave and wave 10 in all ten waves waves partici$(0 / 1)$ $(0 / 1)$ pated (1-10)

\begin{tabular}{|c|c|c|c|c|c|c|}
\hline Male & 0.153 & $(0.313)$ & 0.302 & $(0.272)$ & 0.274 & $(0.393)$ \\
\hline $15-24$ years & $-0.924^{*}$ & $(0.422)$ & $-0.969 *$ & $(0.416)$ & $-1.243^{*}$ & $(0.572)$ \\
\hline $25-34$ years & $-0.959^{*}$ & $(0.381)$ & -0.619 & $(0.357)$ & $-1.249^{*}$ & $(0.509)$ \\
\hline $35-44$ years & -0.701 & $(0.371)$ & -0.117 & $(0.341)$ & -0.585 & $(0.492)$ \\
\hline $45-54$ years & -0.506 & $(0.360)$ & 0.097 & $(0.327)$ & -0.395 & $(0.473)$ \\
\hline $55-64$ years & -0.300 & $(0.311)$ & -0.147 & $(0.281)$ & -0.178 & $(0.408)$ \\
\hline Male, $15-24$ years & -0.363 & $(0.429)$ & -0.428 & $(0.430)$ & $-1.156^{*}$ & $(0.578)$ \\
\hline Male, $25-34$ years & 0.272 & $(0.431)$ & 0.152 & $(0.400)$ & 0.538 & $(0.572)$ \\
\hline Male, 35-44 years & 0.021 & $(0.415)$ & -0.398 & $(0.378)$ & 0.006 & $(0.545)$ \\
\hline Male, $45-54$ years & -0.149 & $(0.412)$ & -0.316 & $(0.370)$ & 0.055 & $(0.535)$ \\
\hline Male, 55-64 years & 0.306 & $(0.421)$ & 0.082 & $(0.369)$ & 0.234 & $(0.533)$ \\
\hline $\begin{array}{l}\text { Education: elementary/lower secondary } \\
\text { school }\end{array}$ & -0.085 & $(0.246)$ & -0.319 & $(0.241)$ & -0.519 & $(0.339)$ \\
\hline Education: vocational school & 0.070 & $(0.188)$ & 0.039 & $(0.178)$ & 0.145 & $(0.256)$ \\
\hline Education: polytechnic, BMS & 0.223 & $(0.247)$ & 0.126 & $(0.230)$ & 0.152 & $(0.329)$ \\
\hline Education: upper secondary school & -0.154 & $(0.206)$ & -0.272 & $(0.201)$ & -0.017 & $(0.285)$ \\
\hline Region: Vorarlberg & 0.182 & $(0.346)$ & -0.379 & $(0.312)$ & 0.146 & $(0.436)$ \\
\hline Region: Tyrol & -0.273 & $(0.239)$ & -0.053 & $(0.228)$ & -0.347 & $(0.324)$ \\
\hline Region: Salzburg & -0.271 & $(0.250)$ & -0.136 & $(0.240)$ & -0.342 & $(0.341)$ \\
\hline Region: Styria & -0.039 & $(0.200)$ & 0.004 & $(0.190)$ & -0.068 & $(0.270)$ \\
\hline Region: Carinthia & 0.102 & $(0.253)$ & -0.033 & $(0.236)$ & 0.018 & $(0.334)$ \\
\hline Region: Upper Austria & -0.271 & $(0.187)$ & -0.307 & $(0.180)$ & -0.225 & $(0.255)$ \\
\hline Region: Lower Austria & -0.108 & $(0.187)$ & 0.118 & $(0.176)$ & 0.055 & $(0.252)$ \\
\hline Region: Burgenland & $-0.869 * *$ & $(0.309)$ & $-0.716^{*}$ & $(0.319)$ & $-1.259 * *$ & $(0.432)$ \\
\hline Household size: 1 person & -0.112 & $(0.164)$ & 0.003 & $(0.156)$ & -0.052 & $(0.222)$ \\
\hline Household size: 2 persons & -0.066 & $(0.141)$ & -0.021 & $(0.135)$ & -0.001 & $(0.192)$ \\
\hline Migration background: yes & 0.066 & $(0.145)$ & 0.204 & $(0.138)$ & 0.382 & $(0.195)$ \\
\hline Employment status: retired & -0.183 & $(0.243)$ & -0.102 & $(0.222)$ & 0.106 & $(0.320)$ \\
\hline Employment status: pupil/student & -0.014 & $(0.255)$ & 0.245 & $(0.278)$ & 0.510 & $(0.367)$ \\
\hline Employment status: others & 0.084 & $(0.203)$ & 0.168 & $(0.195)$ & 0.312 & $(0.277)$ \\
\hline Health risk: respondent & 0.043 & $(0.064)$ & 0.086 & $(0.061)$ & 0.087 & $(0.086)$ \\
\hline Health risk: Austrian population & -0.068 & $(0.081)$ & -0.039 & $(0.077)$ & -0.097 & $(0.110)$ \\
\hline Economic risk: respondent & 0.068 & $(0.056)$ & 0.030 & $(0.053)$ & 0.040 & $(0.076)$ \\
\hline Economic risk: Austrian population & -0.018 & $(0.084)$ & 0.032 & $(0.081)$ & 0.056 & $(0.114)$ \\
\hline Constant & $1.361 * *$ & $(0.472)$ & -0.132 & $(0.438)$ & $7.853 * * *$ & $(0.627)$ \\
\hline$N$ & 1480 & & 1480 & & 1480 & \\
\hline$R^{2}$ & & & & & 0.063 & \\
\hline Pseudo- $R^{2}$ & 0.034 & & 0.041 & & & \\
\hline
\end{tabular}

Entries for models (1) and (2) are logit coefficients; for model (3), unstandardized regression coefficients Standard errors in parentheses $* p<0.05, * * p<0.01, * * * p<0.001$ 


\section{References}

Aichholzer, J., J. Partheymüller, M. Wagner, S. Kritzinger, C. Plescia, J.-M. Eberl, T. Meyer, N. Berk, N. Büttner, H. Boomgaarden, and W.C. Müller. 2020. AUTNES Online Panel Study 2017-2019. Vienna: AUSSDA, https://doi.org/10.11587/QDETRI.

Bækgaard, M., J. Christensen, J.K. Madsen, and K.S. Mikkelsen. 2020. Rallying Around the Flag in Times of COVID-19: Societal Lockdown and Trust in Democratic Institutions. Journal of Behavioral Public Administration. https://doi.org/10.30636/jbpa.32.172.

Bambra, C., R. Riordan, J. Ford, and F. Matthews. 2020. The COVID-19 Pandemic and Health Inequalities. Journal Epidemiological Community Health. https://doi.org/10.1136/jech-2020-21440 1 .

Barrios, J.M., and Y. Hochberg. 2020. Risk Perception Through the Lens of Politics in the Time of the COVID-19 Pandemic. Working Paper. 27008. National Bureau of Economic Research.

Bergmann, M. 2011. IPFWEIGHT: Stata Module to Create Adjustment Weights for Surveys. Statistical Software Components S457353, Boston College Department of Economics. https://ideas .repec.org/c/boc/bocode/s457353.html.

BMAFJ (Bundesministerium für Arbeit, Familie und Jugend). 2020. Arbeitsmarktzahlen [Labour Market Figures]. Published by the Austrian Ministry for Labour, Family and Youth. Retrieved 05 July 2020, https://www.bmafj.gv.at/Services/News/Aktuelle-Arbeitsmarktzahlen.html.

BMSGPK (Bundesministerium für Soziales, Gesundheit, Pflege und Konsumentenschutz). 2020. COVID-19 data provided by the Austrian Ministry for Social Affairs, Health, Care and Consumer Protection. Retrieved 6 July 2020, https:/www.data.gv.at/katalog/dataset/2809273e-d0bc4eb3-a7d3-d01ef2168809.

Boomgaarden, H.G., J. van Spanje, R. Vliegenthart, and C.H. de Vreese. 2011. Covering the Crisis: Media Coverage of the Economic Crisis and Citizens. Economic Expectations', Acta Politica 46(4): 353-379.

Cacioppo, J.T., and W. Patrick. 2008. Loneliness: Human Nature and the Need for Social Connection. New York City: W. W. Norton.

Cornesse, C., A.G. Blom, D. Dutwin, J.A. Krosnick, E.D. De Leeuw, S. Legleye, et al. 2020. A Review of Conceptual Approaches and Empirical Evidence on Probability and Nonprobability Sample Survey Research. Journal of Survey Statistics and Methodology 8(2020): 4-36.

CSH Vienna (Complexity Science Hub Vienna) and TU Wien (Technische Universität Wien). 2020. Corona. How Far We Move. Retrieved 19 July, 2020, https://www.csh.ac.at/coronavirus-howmeasures-work-wirksamkeit-der-massnahmen-oesterreich-june/.

Devine, D., J. Gaskell, W. Jennings, and G. Stoker. 2020. Trust and the Coronavirus Pandemic: What are the Consequences of and for Trust? An Early Review of the Literature. Political Studies Review. https://doi.org/10.1177/1478929920948684.

De Vries, C.E., B.N. Bakker, S. Hobolt, and K. Arceneaux. 2020. Crisis Signaling: How Italy's Coronavirus Lockdown Affected Incumbent Support in Other European Countries. SSRN Scholarly Paper. ID 3606149. Rochester, NY: Social Science Research Network.

Dillman, D.A., J.D. Smyth, and L.M. Christian. 2014. Internet, Phone, Mail, and Mixed-mode Surveys: The Tailored Design Method. New York: Wiley.

Dryhurst, S., C.R. Schneider, J. Kerr, A.L.J. Freeman, G. Recchia, A.M. van der Bles, D. Spiegelhalter, and S. van der Linden. 2020. Risk Perceptions of COVID-19 Around the World. Journal of Risk Research. https://doi.org/10.1080/13669877.2020.1758193.

Egelhofer, J.L., L. Aaldering, J.-M. Eberl, S. Galyga, and S. Lecheler. 2020. From Novelty to Normalization? How Journalists Use the Term 'Fake News' in Their Reporting. Journalism Studies 21: 1323-1343. https://doi.org/10.1080/1461670x.2020.1745667.

Hedström, P., and R. Swedberg. 1998. Social Mechanisms: An Analytical Approach to Social Theory. Cambridge: Cambridge University Press.

Humprecht, E., F. Esser, and P. Van Aelst. 2020. Resilience to Online Disinformation: A Framework for Cross-National Comparative Research. The International Journal of Press/Politics 25(3): 493-516.

Kittel, B., S. Kritzinger, H. Boomgaarden, B. Prainsack, J.-M. Eberl, F. Kalleitner, N.S. Lebernegg, J. Partheymüller, C. Plescia, D.W. Schiestl, and L. Schlogl. 2020a. Austrian Corona Panel Project (SUF edition), https://doi.org/10.11587/28KQNS, AUSSDA. 
Kittel, B., S. Kritzinger, H. Boomgaarden, B. Prainsack, J.-M. Eberl, F. Kalleitner, N.S. Lebernegg, J. Partheymüller, C. Plescia, D.W. Schiestl, and L. Schlogl. 2020b. Austrian Corona Panel Project (OA edition), https://doi.org/10.11587/P5YJ0O, AUSSDA.

Keusch, F. 2015. Why Do People Participate in Web Surveys? Applying Survey Participation Theory to Internet Survey Data Collection. Management Review Quarterly 65(3): 183-216.

Kohler, U., F. Kreuter, and E.A. Stuart. 2019. Nonprobability Sampling and Causal Analysis. Annual Review of Statistics and Its Application 6: 149-172.

Krieger, T., J. Zimmermann, S. Huffziger, B. Ubl, C. Diener, C. Kuehner, and M. Grosse Holtforth. 2014. Measuring Depression with a Well-Being Index: Further Evidence for the Validity of the WHO Well-Being Index (WHO-5) as a Measure of the Severity of Depression. Journal of Affective Disorders 156: 240-244.

Leininger, A., and M. Schaub. 2020. Voting at the Dawn of a Global Pandemic. SocArXiv. https://doi. org/10.31235/osf.io/a32r7.

MacInnis, B., J.A. Krosnick, A.S. Ho, and M.-J. Cho. 2018. The Accuracy of Measurements with Probability and Nonprobability Survey Samples: Replication and Extension. Public Opinion Quarterly 82(4): 707-744.

Oneal, J.R., and A.L. Bryan. 1995. The Rally'round the Flag Effect in U.S. Foreign Policy Crises, 1950-1985. Political Behavior 17(4): 379-401.

Rehm, P. 2016. Risk Inequality and Welfare States: Social Policy Preferences, Development, and Dynamics. Cambridge: Cambridge University Press.

Rudisill, C. 2013. How Do We Handle New Health Risks? Risk Perception, Optimism, and Behaviors Regarding the H1N1 Virus. Journal of Risk Research 16(8): 959-980.

Schwarzer, R. 2008. Modeling Health Behavior Change: How to Predict and Modify the Adoption and Maintenance of Health Behaviors. Applied Psychology 57(1): 1-29.

Sharot, T. 2011. The Optimism Bias. Current Biology 21(23): R941-R945.

Statistik Austria (2019) Austrian Micro Census - Labour Force Survey Yearly Data, July 05, 2020, https://data.statistik.gv.at/web/meta.jsp?dataset=OGD_ake001j_AKEJ_1.

Van Bavel, J.J., K. Baicker, B.S. Boggio, V. Capraro, A. Cichocka, M. Cikara, M.J. Crockett, A.J. Crum, K.M. Douglas, J.N. Druckman, J. Drury, O. Dube, N. Ellemers, E.F. Finkel, J.F. Fowler, M. Gelfand, S. Han, S.A. Haslam, J. Jetten, S. Kitayama, D. Mobbs, L.E. Napper, D.J. Packer, G. Pennycook, E. Peters, R.E. Petty, D.G. Rand, S.D. Reicher, S. Schnall, A. Shariff, L.J. Skitka, S.S. Smith, C.R. Sunstein, N. Tabri, J.A. Tucker, S. van der Linden, P. van Lange, K.A. Weeden, M.J.A. Wohl, J. Zaki, S.R. Zion, and R. Willer. 2020. Using Social and Behavioural Science to Support COVID-19 Pandemic Response. Nature Human Behaviour 4(5): 460-471.

WHO (World Health Organization) (2020). 'Novel Coronavirus (2019-NCoV): Situation Report, 13.' Retrieved 5 July 2020, https://www.who.int/docs/default-source/coronaviruse/situation-repor ts/20200202-sitrep-13-ncov-v3.pdf.

Publisher's Note Springer Nature remains neutral with regard to jurisdictional claims in published maps and institutional affiliations.

Bernhard Kittel is a Professor of Economic Sociology at the University of Vienna working in the fields of experimental justice research, labour market sociology, and comparative welfare regimes.

Sylvia Kritzinger is a Professor for Methods in the Social Sciences at the University of Vienna and principal investigator of the Austrian National Election Study.

Hajo Boomgaarden is a Professor of Methods in the Social Sciences at the University of Vienna with a focus on Text Analysis, using computerized methods of text analysis and multimedia analysis for studying political communication.

Barbara Prainsack is a Professor for Comparative Policy Analysis at the University of Vienna with expertise in the regulatory, social, and ethical dimensions of bioscience, biomedicine, and forensics.

Jakob-Moritz Eberl is a Post-doc Researcher in the Department of Communication at the University of 
Vienna and specialized in research on media discourse and information bias.

Fabian Kalleitner is a Predoc Researcher in the Department of Economic Sociology at the University of Vienna focusing on the sociology of finance, in particular tax attitudes.

Noëlle S. Lebernegg is a Predoc Researcher in the Department of Communication at the University of Vienna studying the effect of automated political communication on political debate and public opinion.

Julia Partheymüller is a Senior Scientist in the Vienna Center for Electoral Research at the University of Vienna studying political communication and voting behaviour.

Carolina Plescia is an Assistant Professor in the Department of Government at the University of Vienna studying comparative electoral behaviour.

David W. Schiestl is a Predoc Researcher at the Department of Economic Sociology at the University of Vienna studying integration processes of refugees.

Lukas Schlogl is a Senior Scientist in comparative policy analysis in the Department of Political Science at the University of Vienna working on economic and technical change and the future of work.

\title{
Affiliations
}

\section{Bernhard Kittel ${ }^{1}$ - Sylvia Kritzinger ${ }^{2} \cdot$ Hajo Boomgaarden $^{3}$ - Barbara Prainsack ${ }^{4}$. Jakob-Moritz Eberl ${ }^{3}$. Fabian Kalleitner ${ }^{1}$. Noëlle S. Lebernegg ${ }^{3}$. Julia Partheymüller ${ }^{5}$. Carolina Plescia ${ }^{2} \cdot$ David W. Schiestl $^{1} \cdot$ Lukas Schlogl $^{4}$}

\author{
Sylvia Kritzinger \\ sylvia.kritzinger@univie.ac.at \\ Hajo Boomgaarden \\ hajo.boomgaarden@univie.ac.at \\ Barbara Prainsack \\ barbara.prainsack@univie.ac.at \\ Jakob-Moritz Eberl \\ jakob-moritz.eberl@univie.ac.at \\ Fabian Kalleitner \\ fabian.kalleitner@univie.ac.at
}

Noëlle S. Lebernegg

noelle.sophie.lebernegg@univie.ac.at

Julia Partheymüller

julia.partheymueller@univie.ac.at

Carolina Plescia

carolina.plescia@univie.ac.at

David W. Schiestl

david.wolfgang.schiestl@univie.ac.at

Lukas Schlog1

lukas.schloegl@univie.ac.at

1 Department of Economic Sociology, University of Vienna, Kolingasse 14-16, 1090 Vienna, Austria 
2 Department of Government, University of Vienna, Kolingasse 14-16, 1090 Vienna, Austria

3 Department of Communication, University of Vienna, Kolingasse 14-16, 1090 Vienna, Austria

4 Department of Political Science, University of Vienna, Universitätsstraße 7, 1010 Vienna, Austria

5 Vienna Center for Electoral Research, University of Vienna, Kolingasse 14-16, 1090 Vienna, Austria 